\section{2nd International Conference on Advanced Research in Teaching and Education}

\title{
Towards a useful conception of the ZPD for language education
}

\author{
Richard S. Lavin ${ }^{1}$ \\ ${ }^{1}$ Prefectural University of Kumamoto, Japan
}

\begin{abstract}
.
The term zone of proximal development (ZPD), based on the writings of Russian psychologist Lev Vygotsky, often appears in language learning research conducted within a socioculturaltheoretic (SCT) framework, yet often it is simply invoked or is used in ways that are radically different from the Vygotsky project without any justification. These include linking the ZPD to the concept of scaffolding, and even claiming that that linkage originated with Vygotsky, again without justification. In this paper, I suggest that it is acceptable to make quite radical adaptations to a theoretical framework that is now almost a century old, but that these should be made with respect towards the historical roots of the theoretical framework, that these modifications need to be acknowledged for what they are, and should be given explicit justification. Specifically, I suggest that the spatial metaphor implied by the ZPD should be made explicit and that we should think flexibly about its structure, with a view to manipulating it in order to generate predictions. This is part of a process of reification, an approach favoured by western scholarship whereby abstract processes are reconceived as concrete entities to enable freer manipulation of concepts and the drawing of links to other concepts for theory construction. In addition, I argue that adult additional language development, despite being different in many ways from children's maturation, has enough similarities to justify the appropriation of the ZPD for its description, especially since it is the only available framework that tracks non-latent development.
\end{abstract}

Keywords: language development; Lev Vygotsky; scaffolding; sociocultural theory; spatial metaphor 


\section{2nd International Conference on Advanced Research in Teaching and Education}

\section{Introduction}

The term zone of proximal development (ZPD), based on the writings of Russian psychologist Lev Vygotsky (1896-1934), often appears in language learning research conducted within a sociocultural-theoretic (SCT) framework, yet often it is simply invoked and the concept is not used particularly productively.

The objective of this paper is to outline a general view of the ZPD that can be meaningfully and profitably leveraged to describe language learning processes and to plan interventions.

There are few mentions in Vygotsky's own writings of the ZPD, and therefore it was left to followers to flesh out the concept. In current research on language learning carried out within an SCT framework, it is possible to discern two strands that this author considers undesirable. (a) the strict/hardline/essentialist strand. This is typically represented by scholars who can read Russian and are aware that the ZPD was used to describe the maturation of young people. They consider it invalid to use the concept for the learning of skills or knowledge in adulthood. Smagorinsky (2009), who deplores "drive-by references" to Vygotsky's work (p. 86) and implores researchers to refrain from "superficial referencing" (p. 75), can be considered a representative of this strand.

(b) the invocationists. Scholars in this strand appeal to the notion of the ZPD to invoke the general idea of progress but do not specify how they conceptualize the ZPD and how the notion of maturation or progress is instantiated/operationalized; in other words, they fail to explain exactly what the notion adds to their account. In Miller's (2011) colourful account, "The acid test to distinguish fact from fad is to remove all mention of Vygotsky and any declared Vygotskian derivatives... from research reports that invoke his name and see if it makes any difference to the aim, design or outcome of the project. (p. 317).

In this paper, I take the view that we need a general conception of the ZPD that lies between these extremes. In other words, departing from the essentialist view, we need to allow for the possibility of sufficient similarities between general maturation in youth and language learning in adulthood to make the leveraging of the same overall framework profitable. At the same time, departing from the invocationists, we want to avoid reliance on subconscious associations in the reader's mind with vague notions of progress, development, or learning, instead specifying our view of the nature of the ZPD and how progress is to be represented in the framework.

\section{Origins}

The ZPD is often defined as "the distance between the actual development level as determined by independent problem solving and the level of potential development as determined through problem solving under adult guidance" (Vygotsky, 1978, p. 86).

This definition is leveraged to capture the general points that learners know (or are capable of) some things and not others; that (hopefully) they will soon come to know some of the things they do not yet know; that teachers or other capable or knowledgeable people can help them learn things they might not otherwise have learned or at least accelerate the learning of certain 


\section{2nd International Conference on Advanced Research in Teaching and Education}

things. Researchers differ in regard to the specificity with which they describe these ideas. Since Wood et al.'s (1976) seminal paper describing scaffolding as an adult "controlling those elements of the task that are initially beyond the learner's capacity, thus permitting him to concentrate upon and complete only those elements that are within his range of competence", references to scaffolding have been ubiquitous. The concept is now commonly associated with the ZPD, although various scholars point out that there is little historical justification for doing so.

Defining scaffolding, Wood et al. (1976) list the following as its essential features: recruiting interest in the task; simplifying the task; maintaining pursuit of the goal; marking critical features and discrepancies between what has been produced and the ideal solution; controlling frustration during problem solving; and demonstrating an idealized version of the act to be performed. Later scholars, such as Walqui (2006), have offered slightly different lists of defining features, with more recent definitions generally emphasizing the ideas of contingency (offering only necessary support) and fading (the teacher reducing support as the learner becomes more capable).

\section{Development}

Most early mentions of the ZPD and scaffolding in the western world focused on teachers or parents offering guidance to children. In later work, there has been a shift in focus towards assistance from peers, and an associated focus on reciprocity. One of the first papers to show that students working in groups could scaffold each other was Donato (1994). In research focusing on peer review in writing classes, De Guerrero and Villamil (2000) talk of pairs of students activating each other's ZPDs.

Poehner (2009) introduces a rather radical change of perspective: Rather than a classroom being a collection of individual ZPDs, he suggests that we could see the whole classroom as a ZPD.

Guk \& Kellogg (2007), comparing the kinds of utterances uttered by teachers in teacherfronted episodes and by students in student-centred activities, find that the teachers' utterances tend to be more grammatically elaborate, in many cases too difficult for the students to produce even though they may be able to understand them all. They suggest that it is profitable to focus attention on the outer and inner edges of the ZPD, since the two types of utterances they identified serve to expand the ZPD both outward (bringing more difficult language within the ZPD as something that students can begin to acquire) and inward (consolidating language that has already been learned to some degree).

As mentioned earlier, typical definitions of the ZPD refer to a "distance" between what a learner can currently accomplish alone and what s/he can do with support. What the learner can do with support is often considered to be the "buds" of development, as it hints at what the learner will be able to do without assistance later. Distance can be represented by a number and is a one-dimensional concept that is incompatible with the idea of a zone. Guk \& Kellogg, also mentioned earlier, talk about inner and outer parts of the ZPD. It is clear that the notion of the ZPD needs a more explicit description and that the various parts or areas evoked need some standard terminology to allow explicit reference to one or another aspect of a ZPD. Lavin \& 


\section{2nd International Conference on Advanced Research in Teaching and Education}

Nakano (2017) propose the terms Zone of Actual Development (ZAD) and Zone of Potential Development (ZPoD) to delineate mastered, or internalized, abilities or knowledge, and knowledge that is beyond current or near-future abilities. With the zones arranged in concentric circles, the ZAD is the innermost and the ZPoD is the outermost circle. The ZPD circle will typically be fairly broad to allow for some internal structure, whether or not explicitly marked with lines.

\section{Controversy}

\subsection{The problem}

Early mentions of the ZPD in Vygotsky's work show that the concept was linked closely with that of mental age (Del Río \& Álvarez, 2007), with Vygotsky attempting to "characterize the initial and terminal thresholds within which development can take place, in order to determine the sensitive periods for different educational goals" (p. 277). Chaiklin (2003) refers to a "generality assumption" (p. 42), which is unjustified because the ZPD is expressly not intended to refer to "instruction in specialized, technical skills such as typing or riding a bicycle" (Vygotsky, 1987, p. 212).

\subsection{Resolving the problem}

Smagorinsky (2018) says that "I believe that Vygotsky's (1978, 1987) account of the ZPD has been reduced to short-term learning due to readers' greater attention to today and tomorrow than to his growth-oriented developmental metaphors" (p. 3). This warning does not, in my view, suggest that we should stop talking about the ZPD in connection with day-to-day language learning. Rather, it encourages us to attempt to link our day-to-day work with longerterm goals. Arguably, this means that we should redouble our efforts to forge sound overarching theories of language development that give clear guidance on how to proceed with teaching on a dayto-day basis. Smagorinsky's, and other scholars', clarifications of the historical roots of the ZPD concept and its meaning within Vygotsky's oeuvre can serve to keep us honest, so to speak, and make sure we see the bigger picture.

It is admirable to seek to avoid trivializing development and simplistic, mechanistic explanations. On the other hand, for the classroom teacher it is useful to have practical tools to quantify (if only in an informal way) day-to-day or moment-to-moment learning that is linked to larger and longer-term goals of development. In the absence of the kind of framework discussed here, it is easy for a divide to develop between daily procedures of getting through

As Belmont (1995) suggests, "tools must fit or must be fitted to the hands that use them" (p. 99). Swain et al. (2015) claim that current scholars "may and should adapt Vygotskian concept to suit the current state of knowledge" (p. xvii), while warning against trivial uses such as publications "with the word sociocultural in the title but which make no reference to Vygotskian principles or concepts" (p. xvii). When using concepts like the ZPD in research, it is important to make a genuine attempt to understand the historical meaning and to clarify one's own interpretation of the concept and any modifications one is introducing. In this way, the reader of the research is at least empowered to reject the research if she feels it is taking excessive liberties with established concepts. 


\section{2nd International Conference on Advanced Research in Teaching and Education}

\subsection{Three possible approaches}

If we do wish to extend the domain of application of the ZPD to adult learning of additional languages, there would appear to be three possible approaches.

\subsubsection{Ignore Vygotsky's words}

The first is to ignore Vygotsky's words and act according to the generality assumption as if Vygotsky did intend the term to be used in this way. This is mentioned here only because it is an oft-used approach. It does not, however, seem to be a very responsible or sustainable one for serious researchers.

\subsubsection{Adopt new terminology}

Another possibility, recognizing that adult learning is very different from child maturation, is to adopt a new term. If we wish to emphasize that, despite fundamental differences, there are also important similarities, we might want to use a term that is reminiscent of ZPD without being the same; if we want to emphasize the differences and deemphasize the similarities, the term might best be very different from "ZPD".

This is not the approach adopted in the bulk of this paper, so it will not be discussed further here; however, I shall revisit the issue briefly in the conclusion.

\subsubsection{Assume that adult language learning is similar to child maturation}

The approach adopted in this paper is to argue that adult learning of additional languages is sufficiently similar to child development to justify using some of the same theoretical apparatus, including the ZPD. A detailed justification of this decision would leave no space to develop the other ideas in this paper, but it is hoped that what follows will be sufficient to convince readers that there is at least a reasonable case supporting this choice.

The general idea behind this approach is that language learning in adulthood is at least to a certain extent a repetition of a process undertaken in childhood. (I make no claims for adult learning in general, only for language learning). Accepting this approach entails rejecting the strongest versions of the critical period hypothesis (CPH; Lenneberg, 1967), according to which the loss of access at a certain age in childhood or adolescence to a hypothesized language acquisition device prevents adult learners from acquiring language in a similar way to the way they learned their native language(s). An emerging consensus on the $\mathrm{CPH}$ (e.g. Abrahamsson, 2013) suggests that it applies only to certain aspects of language such as phonology. We should also note on a more general level that "human psychological and cognitive processes are mediated throughout the lifespan" (Ohta, 2018, p. 650) and that the study of those processes is a legitimate focus of sociocultural research.

A comparatively recent work within an SCT framework concerning language learning and teaching (Lantolf \& Poehner, 2014) refers consistently to "L2 development". The authors relate adult language learning to development and developmental education. Within the Russian Vygotskian tradition, Gal'perin's systemic theoretical instruction (Gal'perin, 1975; Gal'perin, 1992; Gal'perin \& Talyzina, 1965; Leont'ev \& Gal'perin, 1964; Leont'ev \& Gal'perin, 1992) 


\section{2nd International Conference on Advanced Research in Teaching and Education}

is leveraged to explain the process of conceptual development (a key purpose of education in childhood) required to master the grammar of an additional language. A linguistic tradition, cognitive linguistics (e.g. Tyler, 2012), is employed to provide the actual conceptual explanations. An applied linguistic theory, processability theory and its accompanying teachability hypothesis (Pienemann, 2005, 2012, 2015; Pienemann \& Keßler, 2003; Pienemann \& Lenzing, 2015) is employed to conceptualize the notion of staged development (again a key feature of maturation in childhood) and account for the fact that teaching and learning need to "lead development": Learners are not able to learn any arbitrary grammatical features, only those that are one stage beyond their current level.

\section{Advantages of the proposed approach}

\subsection{Acknowledging continuing "becoming"}

Jettisoning the ZPD as a descriptive or explanatory concept for adult language learning would have the advantage of being true to the Vygotskian legacy from the point of view of recognizing its differences from the original domain of application. On the other hand, it would have the disadvantage of ignoring the similarities outlined in Section 4, and necessitating the development of a whole new theoretical apparatus.

Holzman (2018) characterizes the simultaneously "mundane and magical" way in which the ZPD operates by talking about babies thus:

"As soon as infants are born, they enter a physical-social-cultural world in which, barring extreme devastation or deprivation, the people in their lives immediately begin relating to them as simultaneously who they are and who they are not/who they are becoming, i.e., as helpless infants and as members of and participants in the family, community, culture, and the world. Caregivers and relatives carry on conversations with infants, babies, and toddlers before the little ones know how to talk, they play games with them before they know what a game is or its rules, they listen intently to the sounds they make and respond to them." (p. 46)

Holzman (2018) asks: "[H]ow can we become what we're not?" and she answers that "we always are who we are not" (p. 45). On first reading this seems rather mystical, but on reflection it makes some sense. Something like the situation as described for babies above can also apply to anyone taking on a radically new role. An apprentice in any field may receive some moreorless formal explicit guidance, but much of the time is likely to be "in at the deep end", put into the same situations as experts and acting more or less effectively as an expert would, but by relying on intuition and imitation without full understanding of the meanings of what $\mathrm{s} / \mathrm{he}$ is doing. Even comparative veterans can sometimes experience "impostor syndrome", in which they are carrying out the actions they have come to associate with their roles without feeling that they really understand what they are doing. Yet somehow the continued doing eventually leads to mastery or at least some level of proficiency.

\subsection{Reification}

The western intellectual tradition favours reification of processes into entities that are treated as more or less concrete. A prime example from second language acquisition is comprehensible 


\section{2nd International Conference on Advanced Research in Teaching and Education}

input (e.g. Krashen, 1981, 1982). That notion has engendered not only a vast amount of empirical research, but also a large amount of theory generation involving constructs such as noticing, interaction, and comprehensible output. The boldness of Krashen's original claims enabled the development of predictions and refutations.

Making explicit the nature of the metaphorical space that constitutes the ZPD allows us not only to test the utility of various versions of the structure but also to consider the notion of scaffolding in terms of its relation to the space of the ZPD. "Where" does scaffolding take place, and how does it affect (and how is it affected by) the space where it occurs?

\subsection{Capturing invisible progress}

The standard way of measuring progress in language development is to examine learners' own output. The problem is that, in a short space of time, it is quite difficult to see tangible progress in this way. Since the ZPD is concerned with the "buds" rather than the "flowers" of development, it should be possible to examine nascent development. Two proposals currently being developed are mentioned briefly here.

\subsubsection{Scoring according to the amount of support required to make a grammar correction}

Inspired by Aljaafreh \& Lantolf's (1994) seminal paper examining the move from otherregulation to self-regulation, Nakano (2019) has developed a scoring system that also "rewards" any movement towards self-regulation. Students are invited to self-correct free compositions, and a total of four hints, increasing gradually in explicitness, are available as support. A student who self-corrects with none of the hints receives 4 points for the correction, a student needing one hint receives 3 points, a student needing two hints receives 2 points, and a student needing 3 hints receives 1 point. By giving similar assignments with similar classes of errors multiple times in a semester, it is possible to see individual students gradually increasing their scores even though their original compositions have largely the same kinds of errors. It is possible to predict - and of course test the prediction - that the errors receiving 4 points will soon disappear.

\subsubsection{Using transcription to predict future development}

It has been observed in first-year university classes for English majors that students make quite basic grammatical errors (such as omitting plural marking on nouns or omitting $3^{\text {rd }}$-person singular marking on verbs) even when transcribing quotations from books to use in book reviews. Many students decrease the number of those errors drastically over the course of a year within quotations, while still making them in original sentences. It is suggested that accuracy in quotations may be a leading indicator of development in the students' internal grammatical system. If this is borne out empirically, this gives us another possibility for observing progress in the relatively short term that could not be observed simply by checking the grammatical accuracy of students' free compositions. 


\section{2nd International Conference on Advanced Research in Teaching and Education}

\section{Conclusion}

Some recent scholarship, by examining Vygotsky's own pronouncements on the ZPD and considering them in their historical context, have suggested that the concept of the ZPD is designed purely to describe children's development and should not be invoked at all in adult learning. At the same time, much research invokes the ZPD in an unreflective way that adds little to the analysis conducted by the authors.

The present paper takes a middle way. Recognizing the historical roots of the ZPD concept and adapting it in a reflective way, it is possible to leverage the power of the concept while avoiding the dangers of unprincipled ahistoricism.

\section{Acknowledgment}

This work was supported by JSPS KAKENHI Grant Number 19K00853.

\section{References}

Abrahamsson, N. (2013). Critical period hypothesis (CPH). In P. Robinson (Ed.), The Routledge encyclopedia of second language acquisition (pp. 146-151). New York, NY: Routledge.

Aljaafreh, A., \& Lantolf, J. P. (1994). Negative feedback as regulation and second language learning in the zone of proximal development. The Modern Language Journal, 78(4), 465483.

Belmont, J. M. (1995). Discussion: A view from the empiricist's window. Educational Psychologist, 30(2), 99-102.

Bozhovich, E. D. (2009). Zone of proximal development: The diagnostic capabilities and limitations of indirect collaboration. Journal of Russian \& East European Psychology, 47(6), 48-69. doi:10.2753/rpo1061-0405470603

Chaiklin, S. (2003). The zone of proximal development in Vygotsky's analysis of learning and instruction. In A. Kozulin, B. Gindis, V. S. Ageyev, \& S. M. Miller (Eds.), Vygotsky's Educational Theory in Cultural Context (pp. 39-64). Cambridge, UK: Cambridge University Press.

De Guerrero, M. C. M., \& Villamil, O. S. (2000). Activating the ZPD: Mutual scaffolding in L2 peer revision. Modern Language Journal, 84(1), 51-68. doi:10.1111/0026-7902.00052

Donato, R. (1994). Collective scaffolding in second language learning. In J. P. Lantolf \& G. Appel (Eds.), Vygotskian Approaches to Second Language Research (pp. 33-55). Westport, CT: Ablex.

Gal'perin, P. I. (1975). Changing teaching methods is one prerequisite for increasing the effectiveness of the schooling process. Soviet Education, 17(3), 87-92. doi:10.2753/res1060-9393170387 


\section{2nd International Conference on Advanced Research in Teaching and Education}

Gal'perin, P. I. (1992). Linguistic consciousness and some questions of the relationship between language and thought. Journal of Russian \& East European Psychology, 30(4), 8192. doi:10.2753/rpo1061-0405300481

Gal'perin, P. I., \& Talyzina, N. F. (1965). Control of the learning process is basic. Russian Education \& Society (Soviet Education), 7(12), 19-24.

Guk, I., \& Kellogg, D. (2007). The ZPD and whole class teaching: Teacher-led and student-led interactional mediation of tasks. Language Teaching Research, 11(3), 281-299. doi: $10.1177 / 1362168807077561$

Holzman, L. (2018). Zones of proximal development: Mundane and magical. In J. P. Lantolf, M. E. Poehner, \& M. Swain (Eds.), The Routledge handbook of sociocultural theory and second language development (pp. 42-55). New York, NY: Routledge.

Krashen, S. D. (1981). Second language acquisition and second language learning. Oxford, UK: Oxford University Press.

Krashen, S. D. (1982). Principles and practice in second language acquisition. Oxford, UK: Pergamon Press.

Lantolf, J. P., \& Poehner, M. E. (2014). Sociocultural theory and the pedagogical imperative in L2 education: Vygotskian praxis and the research/practice divide. New York, NY: Routledge.

Lavin, R. S., \& Nakano, Y. (2017). Visualizing the concept of the ZPD in language education. The Journal of the Graduate School of Language Literature, Prefectural University of Kumamoto, 10, 39-51.

Lenneberg, E. H. (1967). Biological foundations of language. New York, NY: Wiley.

Leont'ev, A. N., \& Gal'perin, P. I. (1964). Learning theory and programmed instruction. Soviet Education, 10, 7-15. doi:10.2753/RES1060-939307057

Leont'ev, A. N., \& Gal'perin, P. I. (1992). Stage-by-stage formation as a method of psychological investigation. Journal of Russian \& East European Psychology, 30(4), 6080. doi:10.2753/rpo1061-0405300460

Nakano, Y. (2019). A neo-Vygotskian approach to high school writing instruction: Scaffolding towards self-directed learning. Presentation delivered at Prefectural University of Kumamoto, November 5, 2019.

Ohta, A. S. (2018). Sociocultural theory and the zone of proximal development. In J. Herschensohn \& M. Young-Scholten (Eds.), The Cambridge handbook of second language acquisition (pp. 648-669). Cambridge, UK: Cambridge University Press.

Pienemann, M. (2005). An introduction to processability theory. In F. Mansouri (Ed.), Second language acquisition research: Theory-construction and testing (pp. 13-38). Cambridge Scholars Publishing

Pienemann, M. (2012). Processability theory and teachability. In The encyclopedia of applied linguistics (pp. 1-6). https://doi.org/10.1002/9781405198431.wbeal0958 
Pienemann, M. (2015). An outline of processability theory and its relationship to other approaches to SLA. Language Learning, 65(1). https://doi.org/10.1111/lang.12095

Pienemann, M., \& Keßler, J.-U. (2003). Processability theory. In The Routledge handbook of second language acquisition (pp. 228-246). Abingdon, Oxon, UK: Routledge. https://doi.org/10.20581/arele.14.0_21

Pienemann, M., \& Lenzing, A. (2015). Processability theory. In Theories in second language acquisition (2nd ed., pp. 159-179). New York, NY: Routledge. https://doi.org/10.4324/9780203808184.

Poehner, M. E. (2009). Group dynamic assessment: Mediation for the L2 classroom. TESOL Quarterly, 43, 471-491.

Smagorinsky, P. H. (2009). The culture of Vygotsky. Reading Research Quarterly, 44(1), 8595.

Smagorinsky, P. H. (2018). Deconflating the ZPD and instructional scaffolding: Retranslating and reconceiving the zone of proximal development as the zone of next development. Learning, Culture and Social Interaction, 16, 70-75.

Swain, M., Kinnear, P., \& Steinman, L. (2015). Sociocultural theory in second language education: An introduction through narratives. Bristol, UK: Multilingual Matters.

Tyler, A. (2012). Cognitive linguistics and second language learning. New York, NY: Routledge.

Walqui, A. (2006). Scaffolding instruction for English language learners: A conceptual framework. International Journal of Bilingual Education and Bilingualism, 9(2), 159-180.

Wood, D., Bruner, J. S., \& Ross, G. (1976). The role of tutoring in problem solving. Journal of Child Psychology and Psychiatry, 17(2), 89-100. https://doi.org/10.1111/j.14697610.1976.tb00381.x 